\title{
The relation between Chlamydia pneumoniae and atherosclerosis
}

A causative role of infection in the pathogenesis of atherosclerosis was first proposed in 1908 by Sir William Osler. ${ }^{1}$ Although originally this view was not widely accepted, there is now renewed interest in the contributions made by common chronic infections to the pathogenesis and progression of coronary artery disease (CAD). The modern "response to injury" model of atherosclerosis acknowledges that infection may initiate and perpetuate endothelial damage ${ }^{2}$ but the contribution of other mechanisms-metabolic, inflammatory, or haemostatic-also needs to be considered.

The latest infective agent to be implicated in atherosclerosis is Chlamydia pneumoniae, a Gram negative obligate respiratory pathogen. $C$ pneumoniae is a common cause of bronchitis and pneumonia, but infection is usually subclinical and follows a benign course. Up to $60 \%$ of the population have serological evidence of previous infection and individuals are probably infected several times throughout their lives or harbour chronic infection. Because culture of the organism is difficult, confirmation of infection often requires a systemic antibody response to be identified. ${ }^{3}$

\section{Sero-epidemiological studies}

In 1988 a Finnish case-control study showed that after an acute myocardial infarction (MI) most patients (68\%) developed a significant antibody response against an epitope of Chlamydia lipopolysaccharide (LPS), present in only $3 \%$ of a control group and absent in patients with chronic CAD. ${ }^{4}$ Also, stable raised IgG and IgA antibody titres against $C$ pneumoniae (measured by a microimmunofluorescence assay) were significantly higher in the cardiac patients than in the controls. It was suggested that acute MI might be associated with an exacerbation of chronic $C$ pneumoniae infection.

Further support for a causative role was provided by investigating the relation between $C$ pneumoniae antibody titre and subsequent development of CAD in a nested case-control study of sera collected prospectively from the Helsinki Heart Study. ${ }^{5}$ Raised IgA titres against $C$ pneumoniae and the presence of immune-complexes containing $C$ pneumoniae LPS antigen were associated with an increased risk of developing a cardiac event six months later (odds ratio $2 \cdot 3,95 \%$ confidence interval $1 \cdot 3$ to $5 \cdot 2$ ). These associations were independent of age, hypertension, and smoking.

In Seattle, USA, investigators showed that in patients undergoing coronary angiography, an increased IgG titre against $C$ pneumoniae (a marker of previous or chronic $C$ pneumoniae infection) was associated with a twofold increase in angiographically detectable CAD. ${ }^{6}$ Additionally, our group has recently shown a powerful and independent association between seropositivity to $C$ pneumoniae (IgG > 1/64) and prevalent CAD in a community cross-sectional survey. ${ }^{7}$

Serological studies can be criticised in terms of the controls they used, their borderline statistical significances, and their arbitrarily selected $C$ pneumoniae titre cut-offs for seropositivity. Whether an increased antibody titre is a reliable indicator of underlying $C$ pneumoniae infection or simply a reflection of antigenic cross-reactivity, also remains to be resolved. Nevertheless, several laboratories using different techniques and studying patients in different stages of coronary heart disease, have found a consistent association found between disease and $C$ pneumoniae antibody titres or immune-complexes to $C$ pneumoniae.

\section{Evidence from direct plaque examination}

$C$ pneumoniae was detected by both the polymerase chain reaction (PCR) and immunohistochemical techniques within coronary atheroma of necropsy specimens from South Africans. ${ }^{8}$ Of 36 subjects (aged 30-83 years) dying of non-cardiac causes, the organisms were detected in 20 (56\%). C pneumoniae was identified within macrophages, the lipid-rich core of atheromatous plaques, and in smooth muscle cells but not in normal tissue adjacent to the sclerotic lesions or in normal coronary arteries from 11 control patients. Lately, similar diagnostic methods detected $C$ pneumoniae in atherectomy specimens from patients with angina ${ }^{9}$ and from atheromatous arteries in patients with other vascular diseases. ${ }^{10}$

\section{Possible mechanisms of damage}

It remains unclear how $C$ pneumoniae enters atheromatous plaques and whether it has a direct causal role in the atherosclerotic process. $C$ pneumoniae organisms can replicate within alveolar macrophages ${ }^{11}$ and after pulmonary infection may easily gain access to the circulation to spread systemically by being carried by monocytes and macrophages. The organism has been shown to have a ubiquitous extrapulmonary distribution-so far it has been found in arthritic joints ${ }^{12}$ and cerebrospinal fluid ${ }^{13}$ in addition to atheromatous arteries. ${ }^{8-10}$ The consequences of $C$ pneumoniae uptake by macrophages and the mechanisms of damage at the site of the coronary artery remain unknown but there are several possibilities. Firstly, the organism may simply reside in the macrophage without causing any deleterious effects and any association may be purely coincidental (a secondary passenger). Secondly, chronic macrophage infection may contribute to local inflammation and development of atheromatous plaque. This process may be analogous to the pathogenesis of trachoma, where the closely related Chlamydia trachomatis causes blindness as a result of fibrosis which follows conjunctival infiltration by macrophages and lymphocytes. ${ }^{14}$ Fibrosis may develop many years after the original infection and represent a hypersensitivity reaction rather than direct effects of the organism itself. Thirdly, $C$ pneumoniae infection may induce a chronic immune activation mediated by cytokines such as IL-1, IL-6, and TNF-alpha that contribute to direct chronic endothelial cell damage or stimulate the synthesis of acute phase proteins such as fibrinogen ${ }^{15}$ and C-reactive protein. ${ }^{16}$ It is of interest that a 
$57 \mathrm{kDa}$ chlamydial heat shock protein (HSP) has been identified and which has close homology with mycobacterial HSP (linked with atherosclerosis ${ }^{17}$ ) and immune crossreactivity could occur. Finally, because $C$ pneumoniae titres show a weak correlation with important procoagulants such as plasma fibrinogen and factor VIIa concentration $^{15}$ another possibility is that chronic infection leads to an enhanced procoagulant state with increased risk of coronary thrombosis. This could be mediated by monocytederived procoagulants such as tissue factor, ${ }^{18}$ by circulating immune-complexes, or by monocyte-derived cytokines.

\section{Conclusion}

A direct role for chronic chlamydial infection in the pathogenesis of CAD is plausible but has yet to be verified. Evidence in support of causation rather than association will only come from prospective vaccination and antibiotic eradication trials. $C$ pneumoniae infection is common and treatable. If the eradication trials that are now currently underway show conclusive benefit, then Sir William Osler's original hypothesis ${ }^{1}$ will have been supported and antibiotics may play a part in combating the epidemic of coronary artery disease.

Department of Cardiological Sciences,

SANDEEP GUPTA

St George's Hospital Medical School,

London SW17 ORE

1 Osler W. Diseases of the arteries. In: Osler W, ed. Modern medicine: its practice and theory. Philadelphia: Lea and Febiger, 1908;429-47.

2 Ross R. The pathogenesis of atherosclerosis: an update. $N$ Engl $7 \mathrm{Med}$ 1986;314:488-500.

3 Grayston JT, Wang SP, Campbell LA, Kuo C-C. Current knowledge on Chlamydia pneumoniae strain TWAR, an important cause of pneumonia and other acute respiratory diseases. Eur $\mathcal{f}$ Clin Microbiol Infect Dis 1989;8:191-202.

4 Saikku P, Mattila KJ, Nieminen MS, Huttunen JK, Leinonen M, Ekman MR, et al. Serological evidence of an association of a novel chlamydia, TWAR, with chronic coronary heart disease and acute myocardial infarction. Lancet 1988;ii:983-6.

5 Saikku P, Leinonen M, Tenkanen L, Linnanmaki E, Ekman M-R, Manninen V, et al. Chronic Chlamydia pneumoniae infection as a risk factor for coronary heart disease in the Helsinki Heart Study. Ann Intern tor for coronary heart

6 Thom DH, Grayston JT, Siscovick DS, Wang SP, Weiss NS, Daling JR. Association of prior infection with Chlamydia pneumoniae and angiographically demonstrated coronary artery disease. $\mathcal{F} A M A$ 1992;268: 68-72.

7 Mendall MA, Carrington D, Strachan D, Patel P, Molineaux N, Levy J, et al. Chlamydia pneumoniae: risk factors for seropositivity and association with coronary heart disease. $\mathcal{F}$ Infect 1995;30:121-8.

8 Kuo C-C, Shor A, Campbell LA, Fukushi H, Patton DL, Grayston JT. Demonstration of Chlamydia pneumoniae in atherosclerotic lesions of coronary arteries. $\mathcal{F}$ Infect Dis 1993;167:841-9.

9 Muhlestein JB, Hammond EH, Carlquist JF, Radicke E, Thomson MT, Karagounis LA, et al. Increased incidence of Chlamydia species within the coronary arteries of patients with symptomatic atherosclerotic versus the coronary arteries of patients with symptomatic atherosclerotic versus other forms

10 Ong G, Thomas BJ, Mansfield AO, Davidson BR, Taylor-Robinson D. Detection and widespread distribution of Chlamydia pneumoniae in the vascular system and its possible implications. F Clin Pathol 1996;49: 102-106.

11 Black CM, Perez R. Chlamydia pneumoniae multiplies within human pulmonary macrophages (abstract). 90th Annual Meeting ASM Washington DC, American Society of Microbiology 1990, no.D-1, p80.

12 Braun J, Laitkos S, Treherne J, Eggens U, Wu P, Distler A, et al. Chlamydia pneumoniae - a new causative agent of reactive arthritis and undifferentiated oligoarthritis. Ann Rheum Dis 1994;53:100-5.

13 Socan M, Beovic B. Chlamydia pneumoniae and meningoencephalitis. $N$ Engl $\mathcal{Y}$ Med 1994;331:406.

14 Holland MJ, Bailey RL, Ward ME, Morrison R, Whittle HC, Mabey DC. Cell mediated immune responses to Chlamydia trachomatis in scarring Cell mediated immune responses to Chlamydia

15 Patel P, Mendall MA, Carrington D, Strachan DP, Leatham EW, Molineaux N, et al. Association of Helicobacter pylori and Chlamydia pneumoniae infections with coronary heart disease and cardiovascular risk factors. $B M F$ 1995;311:711-4.

16 Mendall MA, Patel P, Ballam L, Strachan D, Northfield TC. C Reactive protein and its relation to cardiovascular risk factors: a population based cross sectional study. BMF 1996;312:1061-5.

17 Xu Q Williet J, Marosi, Kleindienst R, Oberhollenzer F, Kiecl S, et al. Association of serum antibodies to heat shock protein 65 with carotid atherosclerosis. Lancet 1993;341:255-9.

18 Leatham EW, Bath PM, Tooze JA, Camm AJ. Increased monocyte tissue factor expression in coronary disease. Br Heart $\mathcal{7} 1995 ; 73: 10-13$. 